ability among those with lower grade occupations in the manufacturing and trade sectors.

\section{ESTIMATING DISEASE BURDENS AND HEALTH CARE COSTS OF WORK-RELATED MUSCULOSKELETAL DISORDERS IN TAIWAN}

${ }^{1}$ Hsi-Chen Liu, 'Yawen Cheng, ${ }^{2}$ Hsien-Ho Lin. ${ }^{1}$ Institute of Health Policy and Management, College of Public Health, National Taiwan University, Taipei, Taiwan; ${ }^{2}$ Institute of Epidemiology and Preventive Medicine, College of Public Health, National Taiwan University, Taipei, Taiwan

\subsection{6/oemed-2018-ICOHabstracts.428}

Introduction Musculoskeletal disorders (MSDs), encompassing low back pain, inter-vertebral disc disorders, carpal tunnel syndromes, disorders of muscle ligament and fascia, sprains and strains of joints and adjacent muscles, are common among working people. While many occupational factors are known to increase the risks for MSDs, there is little information about the disease burden and healthcare costs of work-related MSDs.

Methods Healthcare utilisation data was extracted from the database of National Health Insurance (NHI), which is a compulsory healthcare insurance program covering up to $99 \%$ of residents of Taiwan. Numbers of outpatient visits and hospitalisation with a primary diagnosis of MSDs and their healthcare costs among the beneficiaries aged 20-65 years old were analysed. Prevalence of self-reported MSDs and exposure prevalence of major ergonomic risk factors by employment sectors were derived from a national representative survey of working people conducted in 2013.

Results The one-year prevalence of self-reported MSDs among working men and women were 58.9\% and 65.9\%, and exposure prevalence rates of any type of ergonomic risk factors among working men and women were $41.2 \%$ and $35.4 \%$, respectively. Annual healthcare expenditures for MSDs were over 158 million USD. Preliminary analyses of disease burden estimated that up to 8500 men and 7000 women developed work-related MSDs that required outpatient treatments or hospitalisation in one year. In contrast, only 434 cases of MSDs were recognised and compensated by the workers' compensation insurance in the same year, suggesting a severe under-recognition of work-related MSDs.

Discussion Work-related MSDs constitutes a major occupational health concern with substantial disease burden and healthcare costs. While it is important to prevent work-related MSDs, it is equally important to readjust financing strategies to ensure that employers take responsibility for healthcare costs due to occupational factors.

\section{RETURN TO WORK AND WORK RETENTION IN CANCER IN FINLAND - SEVEN MOST COMMON CANCERS}

Kirsti Husgafvel-Pursiainen*, Eira Viikari-Juntura, Taina Leinonen, Svetlana Solovieva. Finnish Institute of Occupational Health, Helsinki, Finland

10.1136/oemed-2018-ICOHabstracts.429

Introduction Recent report by EU-OSHA reviews research on rehabilitation and return to work after cancer (Tikka, et al., 2017). About half of the annual 3.2 million new cases of cancer occur in working-age individuals. Further, in Europe in
2012, over half of the overall cancer burden was due to breast, colorectal, prostate, and lung cancer.

Methods Our study was based on nation-wide register information on ill-health benefits as well as employment and unemployment periods for 2005-2009 in Finland. Eligible subjects had the first full-time sickness absence (fSA) due to cancer diagnosis (prostate/breast, lung, colon, bladder, nonmelanoma skin, melanoma, non-Hodgkin lymphoma), were 18-57 years of age and employed on the last day of the index sickness absence spell. They were followed from the first day of fSA until the first return to work (RTW) or other event (partial work disability, rehabilitation, fSA, full work disability retirement [fWDR], unemployment, or exit from labour force).

Result Altogether 9162 eligible subjects (2839 men; 6323 women) were identified. For several common cancers, $\geq 80 \%$ of male and female patients were able to return to work. In lung cancer, with low survival rates, only around 25\%-30\% returned to work. After RTW, in prostate cancer and breast cancer, $70 \%$ were at work after 48 months. As to time spent in different statuses, $80 \%-85 \%$ of prostate cancer patients returned to work in 4-5 months, with fWDR and unemployment emerging eventually at 5\%-7\% level. Similarly, for breast cancer, $80 \%$ of the subjects returned to work in 10 months, with around 7\% with fWDR from that onward.

Discussion Overall, for most common male and female cancers, around $80 \%$ of subjects were able to return to work within the first 4-12 months and 50\%-60\% were at work at the end of follow-up, with the exception of lung cancer, a fatal disease.

\section{OCCUPATIONAL EXPOSURE TO MERCURY IN A SMALL SCALE GOLD MINING WORKERS AND FAMILIES IN HANDENI, TANZANIA}

Aiwerasia Vera Ngowi*, Elida Wilfred Macha. Muhimbili University of Health and Allied Sciences, Dar-es-Salaam, Tanzania

\subsection{6/oemed-2018-ICOHabstracts.430}

Introduction Mercury is a highly dangerous neuro-toxicant. High exposures in artisanal gold mining have significant health and environmental impacts. We aimed to determine mercury exposure levels and to assess the health effects among the artisanal gold miners and their families

Methods A cross sectional descriptive study was conducted on 292 miners and their families. Interviews and medical examinations were conducted. A sample of 30 participants with history of mercury use had mercury analysis performed on their hair, urine and blood by Inductively Coupled Plasma Optical Emission Spectrometry. Data analysis was done using Epi-Info. Result The mean mercury levels in urine and blood were $46.3 \mu \mathrm{g} / \mathrm{L}$ and $14.5 \mu \mathrm{g} / \mathrm{L}$ respectively, with a maximum of $74.7 \mu \mathrm{g} / \mathrm{L}$ for urine and $56.7 \mu \mathrm{g} / \mathrm{L}$ for blood. Out of 21 urine samples, $10(47.6 \%)$ exceeded the maximum World Health Organisation (WHO) acceptable level of $50 \mu \mathrm{g} / \mathrm{L}$. Out of 25 blood samples, 13 (52\%) exceeded the WHO normal range of $5-10 \mu \mathrm{g} / \mathrm{L}$. All hair samples were below the detection limit of $0.01 \mathrm{ppm}$. Miners engaged in amalgamation and burning of amalgam had higher mean mercury levels in urine $(54 \mu \mathrm{g} / \mathrm{L}$, $\mathrm{p}=0.03)$ and blood $(14.3 \mu \mathrm{g} / \mathrm{L}, \mathrm{p}=0.9)$ than others. Tremor of the eyelid $(30 \%)$ was significantly higher $(\mathrm{p}<0.005)$ in miners than non-miners. Miners recorded blue line in gums (34\%), 
blue coloured ring in periphery of iris (11\%), dysmetria (9\%), gingivitis $(7 \%)$, intention tremor $(5 \%)$, decreased mental labial reflex (5\%), decreased Babinski reflex (5\%), ataxia (3\%) and decreased ankle jerk reflex (2\%). About 50\% of participants with clinical signs of mercury intoxication were found to have mercury levels in their blood and urine above WHO standards.

Discussion Our findings show higher levels of mercury in urine, blood and hair above recommended values which correspond to the neurological symptoms. There is a need for interventions on the reduction of the mercury exposure among workers.

\section{TRENDS AND PATTERNS OF FATAL OCCUPATIONAL INJURIES AND COMPENSATED OCCUPATIONAL DISEASES IN TAIWAN, 1998-2016}

Chung-Yen Chen*, Yawen Cheng. Institute of Health Policy and Health Management, National Taiwan University, Taipei, Taiwan

\subsection{6/oemed-2018-ICOHabstracts.431}

Introduction This study described the trends and compensation patterns of fatal occupational injuries and occupational diseases in Taiwan and examined the similarities and differences with that of selected countries.

Methods Numbers, occurrence rates and compensation benefits of fatal occupational injuries and occupational diseases in Taiwan were obtained from official statistics for the period from 1998 to 2016. Also obtained were official statistics on the numbers and major types of compensated occupational diseases from Japan, South Korea and selected European countries.

Results From 1998 to 2016, the coverage of the workers' compensation insurance program expanded from $79.6 \%$ to $86.7 \%$, and occupational fatality had declined substantially but was still higher as compared to other developed countries. Analyses of the levels of claimants' compensation benefits showed that the average amount of benefits for fatal cases had been reduced steadily. Despite of recent efforts by the government in improving the recognition of occupational disease, the compensation rates of occupational diseases remained low (8.18 per 100000 insured). Musculoskeletal disorders were the most dominant type of occupational disease in Taiwan, accounting for up to $66 \%$ in 2016 , following by respiratory diseases $(17 \%)$ and stress-related cerebrovascular and cardiovascular diseases (10\%).

Discussion The observed improvement in occupational fatality had been accompanied by a downward trend in average compensation benefits, suggesting a shift of occupational fatalities toward low-wage groups. On one hand, under-recognition and under-compensation of occupational diseases were severe, that may due to multiple institutional and administrative barriers as well as lower social awareness on the work-relatedness of disease causality. On the other hand, the high visibility of cerebrovascular and cardiovascular events suggested the social concerns over long working hours and heavy workloads might have played a significant role in the recognition of overworkrelated occupational diseases.

\section{9 LONGITUDINAL ASSOCIATIONS OF SHIFT WORK WITH DEPRESSIVE DISORDERS - A SYSTEMATIC REVIEW AND META-ANALYSIS}

Peter Angerer*, Renate Schmook, Jian Li. Institute for Occupational, Social, and Environmental Medicine, Medical Faculty, Heinrich-Heine-Universität Düsseldorf, Germany

\subsection{6/oemed-2018-ICOHabstracts.432}

Background Shift work, especially night shift work, causes disturbance of sleep, tiredness, and reduced well-being, as it interferes with the circadian chronobiological rhythm and social activities. Shift increases the risk of coronary heart disease and diabetes. Whether shift work increases the risk of depressive disorders is controversial. Whereas crossectional studies indicate an increased risk, longitudinal studies are inconclusive.

Methods Based on a systematic and extensive literature research in PubMed, Scopus, PsycINFO, PSYNDEX, and Medpilot, 5682 publications dealing with shift work and mental illness were identified until 2016 December. According to predefined selection criteria eleven high quality studies with longitudinal design reporting the relationships between shift work including night work and depressive disorders were analysed.

Results Three out of four studies, restricted in health care professions, predominantly nurses, found no significant relationships between shift work including night work and depressive disorders within period of two-year follow-up. Another five studies among employees working in sectors other than health care yielded indications for an increased risk, during period of up to ten years follow-up, however, a consistent pattern of longitudinal associations was not observed. Supplementary meta-analysis, including five studies, also indicated that shift work elevated the risk of depressive disorders by 42\% (95\% confidence interval 0.92-2.42). Adverse psychosocial work conditions may partly explain the associations.

Conclusions Even though the findings indicate an increased risk of depressive disorders by shift work or night work, at least outside the health care sector, the evidence is too weak to give general medical advice against shift work with respect to employees' mental health. Rather, it seems adequate to take an individualised approach with continuous support from occupational physicians and practical consideration on psychosocial stress factors that are linked to shift work. How these finding are incorporated in the German guidelines for shift work that are currently updated will be reported.

\section{EPIDEMIOLOLOGICAL PROFILE OF LABOR DISABILITY - IN PARATY}

${ }^{1}$ L Rozemberg, ${ }^{2} \mathrm{D}$ Rozemberg. ${ }^{1}$ Hospital Stela Maris, Caraguatatuba, Brazil; ${ }^{2}$ Ministry of Social Security, Paraty, Brazil

\subsection{6/oemed-2018-ICOHabstracts.433}

Introduction The causes of temporary incapacity, established through official expertise (Ministry of Welfare) in Paraty unit, Brazil, are evaluated by establishing the epidemiological profile aiming the proposal of preventive measures.

Methods Retrospective study of all skills that generated financial support for disability in the year 2016 in the city of 